\title{
Structural and Dielectric Properties of Sintering Zinc Oxide Bulk Ceramic
}

\author{
Mariem Chaari*, Adel Matoussi, Zouheir Fakhfakh
}

${ }^{1}$ Laboratory of Composite Ceramic and Polymer Materials, Scientific Faculty of Sfax, Tunisia, Africa.

Email: ${ }^{*}$ m_chaari@yahoo.fr

Received April 2 ${ }^{\text {nd }}, 2011$; revised April 22 ${ }^{\text {nd }}, 2011$; accepted April 30 $0^{\text {th }}, 2011$.

\begin{abstract}
Undoped zinc oxide $(\mathrm{ZnO})$ has been prepared at various growth temperatures by conventional sintering process. The morphology and crystalline properties of $\mathrm{ZnO}$ pellets were examined by scanning electron microscopy, atomic force microscopy and X-ray diffraction. It has revealed that the grain size and surface roughness tends to increase by increasing the sintering temperature. XRD analysis showed that all samples are polycrystalline with a hexagonal wurtzite structure. The alignment of $\mathrm{ZnO}$ grains along the (10.0) plane was enhanced as the temperature increased. Interestingly, the compressive stress was found to decrease drastically from $-0.62 \mathrm{GPa}$ at $700^{\circ} \mathrm{C}$ to $-0.2 \mathrm{MPa}$ at $1000^{\circ} \mathrm{C}$. This improvement in film structure seems to enhance considerably the dielectric properties for the samples sintering at high temperatures. Results show an increase of dielectric constant and a decrease of electrical resistivity when increasing the sintering temperature.
\end{abstract}

Keywords: Zinc Oxide, Sintering Process, Micro Strain, Impedance Spectroscopy

\section{Introduction}

During the last few decades, zinc oxide $(\mathrm{ZnO})$ has attracted much interest in science and technology due to its versatile properties such as transparency in the visible range, direct band gap $(3.37 \mathrm{eV})$, absence of toxicity, abundance in nature, etc. These characteristics find a wide range of applications in opto-electronic and electronic devices [1-7]. For example, it used in solar cells [1], transparent conducting films, chemical sensors [2,3], varistors [4,5], light-emitting diodes[6], laser diodes [7], etc.

The preparation of high quality $\mathrm{ZnO}$ thin films has been the subject of continuous research. Many techniques are used for preparing zinc oxide such as: RF sputtering [8], chemical vapour deposition [9], sol-gel process [10], carbothermal reduction method [11] and pressurized melt growth [12,13], among others. The conventional sintering process has the advantages of being cheap, easy-to-use, safe and able to be implemented in a standard laboratory. It is well known that the optoelectronic properties of $\mathrm{ZnO}$ are affected by the preparation conditions such as working pressure, substrate temperature, types of substrates, thickness of the films and annealing temperature.

The present paper is devoted to examine the influence of sintering temperature on the structure, mor- phological and the dielectric properties of $\mathrm{ZnO}$ tablets.

\section{Experimental Procedure}

Undoped $\mathrm{ZnO}$ pellets were prepared by the conventional sintering technique in an atmospheric heated furnace using zinc oxide powders (Aldrich-GmbH, purity $\approx 99 \%$ ). The $\mathrm{ZnO}$ powders were first milled in an agate mortar and heated in air at annealing temperature of $300^{\circ} \mathrm{C}$ for 2 hours to evaporate the water and remove the organic residuals. The obtained powders were then pressed into pellet disks (of about $1 \mathrm{~mm}$ thickness and $8 \mathrm{~mm}$ diameter) and sintered at various temperatures $\left(700^{\circ} \mathrm{C}-1000^{\circ} \mathrm{C}\right)$ in ambient air for 3 hours. Finally, these pellets were rapidly quenched to room temperature in air in order to freeze the structure. The crystalline structure and surface morphology of the sintered specimens were characterized by X-ray diffraction (XRD), scanning electron microscopy (SEM) and atomic force microscopy (AFM). The spectrometer dielectric was used to characterize the dielectric properties of the obtained samples.

\section{Results and Discussions}

\subsection{Structural Properties}

The $\mathrm{ZnO}$ structure is examined by $\theta-2 \theta \mathrm{X}$-ray diffraction (XRD) measurements. Figure 1 shows the XRD 
patterns of $\mathrm{ZnO}$ prepared at growth temperature ranging from $700^{\circ} \mathrm{C}$ to $1000^{\circ} \mathrm{C}$. All the samples exhibit a polycrystalline hexagonal structure. The peaks are identified to (10.0), (00.2), (10.1), (10.2), (11.0) and (10.3) plane reflections for wurtzite phase of $\mathrm{ZnO}$ according to the standard JCPDS data file (No. 36-1451). One can see that the $\mathrm{ZnO}$ growth appears to be randomly oriented along the (10.1) plane instead of c-axis (00.2) direction.

In order to evaluate the texture coefficient and the percentages in volume of oriented crystallites in the $<\mathrm{hk}$.l $>$ direction, we have used the well-known formula reported in Ref. [14] and results are given in Table 1.

It is found that the highest value of texture coefficient (TC) corresponds to (10.1) plane which contributes about $47 \%$ of oriented $\mathrm{ZnO}$ grains. We notice a slight decrease of the contribution of (00.2) phase on detriment to the (10. 1) one as the sintering temperature is varied from $700^{\circ} \mathrm{C}$ to $1000^{\circ} \mathrm{C}$. Figure 2 shows that the intensity of the (10.1) peak compared to the neighboring (10.0) and (00.2) increases by increasing the sintering temperature from $700^{\circ} \mathrm{C}$ to $1000^{\circ} \mathrm{C}$. This result indicates that $(10.1)$ is the preferred orientation of $\mathrm{ZnO}$ pellet growth. In addition, the full width at half maximum (FWHM) for $\mathrm{ZnO}(10.1)$ peak decreases from $0.24^{\circ}$ to $0.12^{\circ}$ when the temperature increases from $700^{\circ} \mathrm{C}$ to $1000^{\circ} \mathrm{C}$ respectively.

The dependence of the growth temperature on the grain size, the angle position and FWHM for $\mathrm{ZnO}(00.2)$ diffraction peak are illustrated in Table 2. The average grain size of $\mathrm{ZnO}$ is calculated using the Scherer's Equation [15]:

$$
\mathrm{D}=\frac{0.9 \lambda}{\mathrm{B} \cos \theta}
$$

where $\mathrm{D}$ is the grain size, $\lambda$ is the wavelength of the $\mathrm{X}$-ray radiation used, $\mathrm{B}$ is the full width at half maximum (FWHM) of the diffraction peak and $\theta$ is the Bragg diffraction angle of the XRD peak.

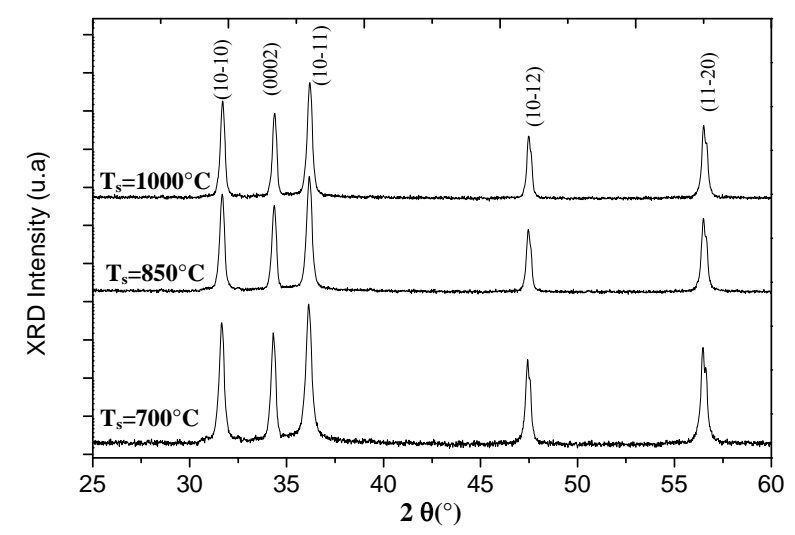

Figure 1. XRD patterns of ZnO prepared at various Sintering temperatures.

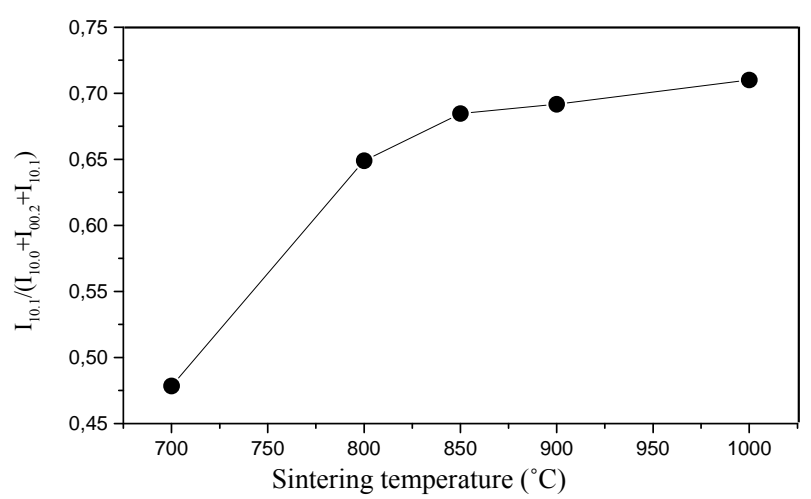

Figure 2. Evolution of intensity ratio of XRD peaks as a function of sintering temperature.

The crystallite size increases from approximately 38 $\mathrm{nm}$ at $700^{\circ} \mathrm{C}$ to $52 \mathrm{~nm}$ at $900^{\circ} \mathrm{C}$. As the temperature increases, we observe a neat decrease of the full width at half maximum of the (00.2) peak. Furthermore, the (00.2) peak position shifts to higher angles and reaches the value $34.408^{\circ}$ of free-strained $\mathrm{ZnO}$ film [16].

Here, it must be pointed that the crystal quality of $\mathrm{ZnO}$ can be improved at higher sintering temperature [17-19].

This behavior can be explained by the reduction of the density defects and atom vacancies caused by the increase of the diffusion of oxygen and zinc atoms at elevated temperature. According to Bachari [20], the lack of oxygen atoms may result in the growth of non-stoichiometric thin films and bad crystalline phases.

It has been reported that the crystalline properties and alignment of the $\mathrm{ZnO}$ thin films depends strongly on the substrate temperature and the $\mathrm{O}_{2}$ concentration during growth. Vimalkumar et al. [21] showed that with increase in the spray pyrolysis rate orientation of $\mathrm{ZnO}$ grains changed from (10.1) to (00.2) plane. Matsuka and Ono [22] have observed that the increase of oxygen partial pressure from 0 to $0.12 \mathrm{~Pa}$ leads to change of crystalline orientation from (10.1) to (00.2) plane. Prasada et al. [23] showed that $\mathrm{ZnO}$ grows randomly along the (10.1), $(00.2)$ and (10.0) orientations. They found that the stress value decreases whereas the particle size increases as the growth temperature increased.

In our case, the lattice strain $\varepsilon_{z z}$ and residual stress $\sigma$ in the grown $\mathrm{ZnO}$ samples are estimated using the following expressions [24]:

$$
\sigma=\frac{2 \mathrm{C}_{13}^{2}-\mathrm{C}_{33}\left(\mathrm{C}_{11}+\mathrm{C}_{12}\right)}{2 \mathrm{C}_{13}} \times \varepsilon_{z z}
$$

and

$$
\varepsilon_{z z}=\frac{\mathrm{c}-\mathrm{c}_{0}}{\mathrm{c}_{0}}
$$


Table 1. Texture coefficient and percentages of oriented crystallites in $<$ hk.l $>$ direction.

\begin{tabular}{cccccccc}
\hline & \multicolumn{3}{c}{ Texture coefficient } & \multicolumn{3}{c}{ Percentage of oriented crystallites $(\%)$} \\
Ts $\left({ }^{\circ} \mathrm{C}\right)$ & \multicolumn{2}{c}{$\mathrm{TC}(10.0) \mathrm{TC}(00.2) \mathrm{TC}(10.1)$} & & \multicolumn{2}{c}{$(10.0)$} & $\chi(00.2)$ & $\chi(10.1)$ \\
& \pm 0.0005 & \pm 0.0003 & \pm 0.0004 & $12.96 \pm 0.008$ & $25.99 \pm 0.011$ & $46.11 \pm 0.012$ \\
& 0.648 & 1.299 & 2.355 & $12.78 \pm 0.011$ & $26.24 \pm 0.020$ & $47.10 \pm 0.009$ \\
800 & 0.639 & 1.312 & 2.345 & $13.09 \pm 0.007$ & $24.98 \pm 0.006$ & $47.38 \pm 0.004$ \\
900 & 0.655 & 1.249 & 2.369 & $12.91 \pm 0.005$ & $25.36 \pm 0.004$ & $48.13 \pm 0.003$ \\
1000 & 0.645 & 1.268 & 2.406 & & & \\
\hline
\end{tabular}

Table 2. Variations of grain size and FWHM for $\mathrm{ZnO}(00.2)$ reflection with temperature.

\begin{tabular}{cccc}
\hline Ts $\left({ }^{\circ} \mathrm{C}\right)$ & $\begin{array}{c}\text { FWHM of the } \\
(00.2) \text { peak }\left({ }^{\circ}\right)\end{array}$ & Diffraction angle $2 \theta\left(^{\circ}\right)$ & $\begin{array}{c}\text { Grain size } \\
\text { D }(\mathrm{nm})\end{array}$ \\
\hline 700 & 0.236 & 34.323 & $38.221 \pm 0.021$ \\
800 & 0.209 & 34.353 & $41.323 \pm 0.018$ \\
850 & 0.183 & 34.386 & $47.194 \pm 0.011$ \\
900 & 0.168 & 34.403 & $51.407 \pm 0.017$ \\
1000 & 0.172 & 34.420 & $50.212 \pm 0.013$ \\
\hline
\end{tabular}

where $\mathrm{c}_{0}$ and $\mathrm{c}$ are the lattice parameters of unstrained and the prepared $\mathrm{ZnO}$ samples respectively. $\mathrm{C}_{11}=209.7$ $\mathrm{GPa}, \mathrm{C}_{12}=121.1 \mathrm{GPa}, \mathrm{C}_{13}=105.1 \mathrm{GPa}$ and $\mathrm{C}_{33}=210.9$ $\mathrm{GPa}$ are the elastic stiffness constants of bulk $\mathrm{ZnO}$ [23].

Figure 3 shows the variation of lattice strain and residual stress in $\mathrm{ZnO}$ as a function of the growth temperature. The sample sintered at $700^{\circ} \mathrm{C}$ has larger strain and stress values. One can see that the residual stress is compressive which decreases negatively from $-0.62 \mathrm{GPa}$ at $700^{\circ} \mathrm{C}$ to $-0.2 \mathrm{MPa}$ at $1000^{\circ} \mathrm{C}$. This means that elevated temperature in the range $900^{\circ} \mathrm{C}-1000^{\circ} \mathrm{C}$ are favoured to obtain better crystalline quality of $\mathrm{ZnO}$ prepared by conventional sintering process. According to Prasada [23], the measured stress in $\mathrm{ZnO}$ is attributed mainly to intrinsic origins introduced by the presence of impurities defects and lattice distortions in the crystal. The extrinsic stress induced by the lattice and the thermal mismatches will not be generated because the pellet is thicker $(1 \mathrm{~mm}-2 \mathrm{~mm})$ and because of the non-use of growth substrate in our experiment.

Moreover, it is shown that the intrinsic stress appears frequently in nonstoichiometric films $[23,25]$. This seems to be consistent with energy dispersive X-ray (EDX) analysis presented in the Table 3 . It is seen clearly that the sample composition became more stoichiometric with increasing the sintering temperature. For all the samples, the level of incorporation impurity is reduced to an amount lesser than $1.5 \%$ and the percentages of oxygen and the zinc are nearly equal. Consequently, it reveals that the growth at high temperature $\left(>1000^{\circ} \mathrm{C}\right)$ can strongly enhance the physicochemical properties and thus improve the crystallinity of the $\mathrm{ZnO}$ films.

\subsection{Morphological Properties}

Figure 4 shows the scanning electron micrographs of $\mathrm{ZnO}$

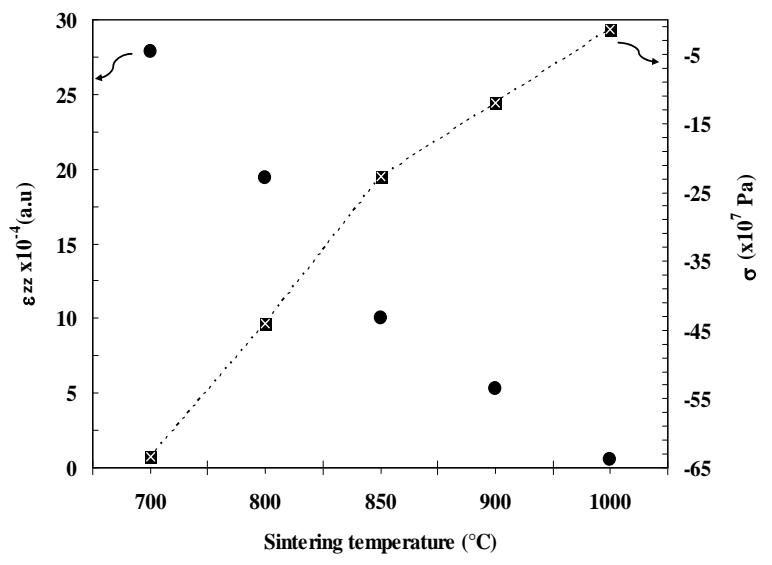

Figure 3. Variation of lattice strain and residual stress in ZnO tablets.

Table 3. EDX analysis of the Zinc oxide samples.

\begin{tabular}{ccc}
\hline $\begin{array}{c}\text { Sintering } \\
\text { temperature }\left({ }^{\circ} \mathrm{C}\right)\end{array}$ & $\mathrm{O}($ at \%) & $\mathrm{Zn}($ at \%) \\
\hline 700 & $50.568 \pm 0.008$ & $48.144 \pm 0.006$ \\
850 & $50.043 \pm 0.005$ & $48.244 \pm 0.009$ \\
900 & $49.752 \pm 0.011$ & $48.76 \pm 0.011$ \\
1000 & $49.412 \pm 0.012$ & $49.78 \pm 0.013$ \\
\hline
\end{tabular}

pellets sintered at $850^{\circ} \mathrm{C}, 900^{\circ} \mathrm{C}$ and $1000^{\circ} \mathrm{C}$. For all samples, the surface is rough and presents grains of crystallites having very varied shapes and nanometric sizes. These crystallites are randomly distributed and irregularly disoriented. With increasing the sintering temperature, the grain size is found to increase whereas its density decreases resulting from conglomeration or coalescence of smaller grains.

Here, it is evident that the sintering temperature exercises strong effects on the surface morphology and the crystal quality of $\mathrm{ZnO}$ powders. 

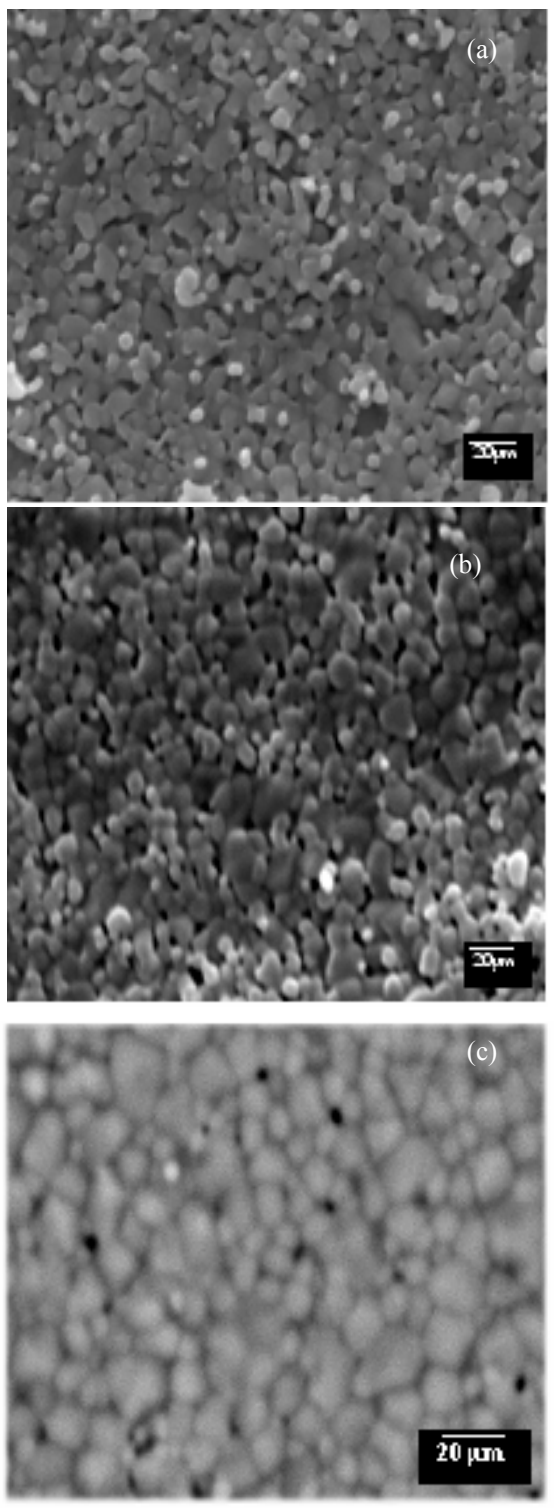

Figure 4. Plan view of SEM micrographs of $\mathrm{ZnO}$ pellets sintered at $850^{\circ} \mathrm{C}(\mathrm{a}) ; 900^{\circ} \mathrm{C}(\mathrm{b})$; and $1000^{\circ} \mathrm{C}$ (c).

From AFM analyses, the rms roughness increases from $9 \mathrm{~nm}$ to $68 \mathrm{~nm}$ as the deposition temperature increases from $700^{\circ} \mathrm{C}$ to $1000^{\circ} \mathrm{C}$. This agrees well with the results of XRD measurements. We surmise that at high temperature, the atoms have enough diffusion activation energy to occupy the proper sites in the crystal lattice and grains with the lower surface energy become larger at high temperature [26]. These results show that the high temperature enhances the coalescence of grains and thus the lateral growth of $\mathrm{ZnO}$ along the $<10.1>$ direction.

\subsection{Dielectric Analysis}

Figure 5 presents the variation of the dielectric constant measured at room temperature for different frequency as a function of the sintering temperature. The dielectric constant was decreased as the measuring frequency increased. For the sample sintered at $1000^{\circ} \mathrm{C}$ the $\varepsilon$ value decreased from 900 at $1 \mathrm{~Hz}$ to 12.27 at $2 \mathrm{kHz}$ and to 4 at $1 \mathrm{MHz}$. Also, it shows an increase tendency of all the dielectric constants with increasing the sintering temperature from $700^{\circ} \mathrm{C}$ to $1000^{\circ} \mathrm{C}$.

These behaviours may be attributed to the enhancement of grain size, compactness and the structural quality of the material [25-27]. Figure 6 illustrates the evolution of electrical resistivity with increasing the sintering temperature. The resistivity was first decreased reaching a minimum value $4 \times 10^{9} \Omega \cdot \mathrm{cm}$ at $850^{\circ} \mathrm{C}$ and then increased with increasing temperature. A similar behaviour has been observed by Gomes [28] and Olivera [29] in Ga- doped and F-doped $\mathrm{ZnO}$ thin films, respectively.

The measured values of resistivity are in range $10^{9}$. $10^{10} \Omega \cdot \mathrm{cm}$ which indicates that our prepared $\mathrm{ZnO}$ bulk possess an insulating behaviour rather than n-type semi-

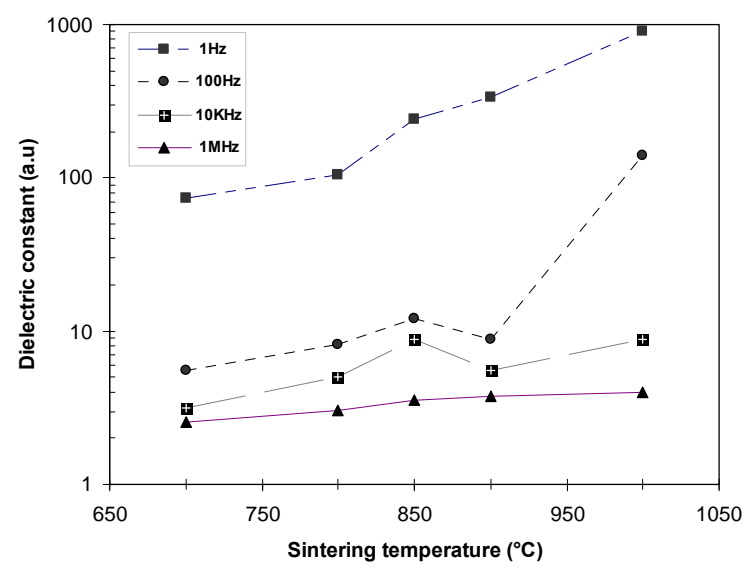

Figure 5. Variation of the dielectric constant as a function of the sintering temperature.

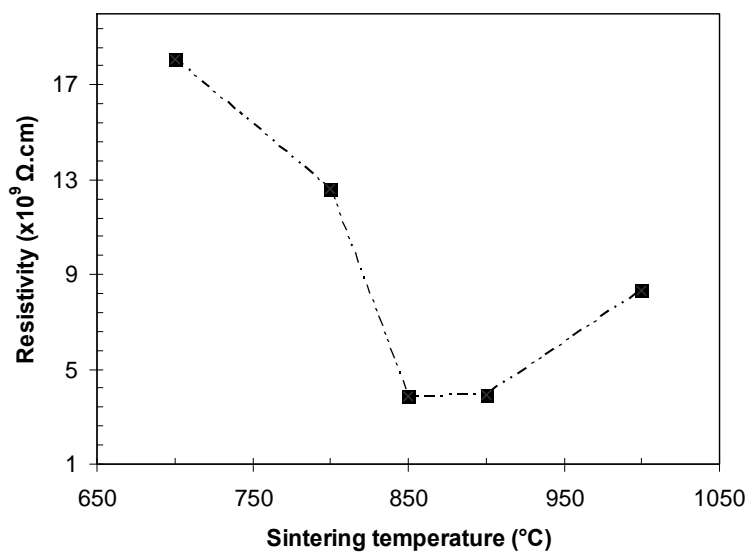

Figure 6. Evolution of electrical resistivity versus the sintering temperature. 
conductor character. However, the decrease of resistivity with elevation of growth temperature is due, on the one hand, to both the improvement in the pellet structure and the reduction of grain boundaries which enhance the free electron mobility [30]. On the other hand, the reduction in the resistivity can also be due to the non-stoichiometry of the film and the presence of residual impurities $(\mathrm{K}, \mathrm{Ca}$, $\mathrm{S}$, and $\mathrm{Fe}$ ) which can substitute the $\mathrm{Zn}$ atoms and/or be incorporated in oxygen vacancies [28,29,31].

For samples sintered at higher temperatures, the increase in resistivity can be associated to more appropriate stoichiometry, the increase of $\mathrm{ZnO}$ grain size and the scattering of free carriers at grain boundaries in polycrystalline $\mathrm{ZnO}$ pellets [23-25]. Here, it is important to notice that high temperature can enhance the crystalline and the dielectric properties of $\mathrm{ZnO}$ pellets.

As schown in Figure 7, the lowest value of dielectric loss at higher frequencies $\left(\operatorname{tg} \delta=6.6 \times 10^{-2}\right)$ is found for the $\mathrm{ZnO}$ sample sintered at $900^{\circ} \mathrm{C}$. Due to their good dielectric properties, low dielectric loss, and high electrical resistivity. $\mathrm{ZnO}$ can be used as a promising material for fabrication of dielectric varistors and transparent electrodes in solar cells.

\section{Conclusions}

In this paper, we study the effect of growth temperature on the structural and dielectric properties of zinc oxide prepared by conventional sintering process. The morphology and the crystalline characteristics of $\mathrm{ZnO}$ films were examined by scanning electron microscopy, atomic force microscopy, and X-ray diffraction. It has revealed that the grain size and surface roughness tends to increase and that the crystalline quality of $\mathrm{ZnO}$ film is better enhanced by increasing the sintering temperature.

XRD analysis showed that all films are polycrystalline with a hexagonal wurtzite structure and randomly oriented (10.1) direction. The residual stress in $\mathrm{ZnO}$ sample

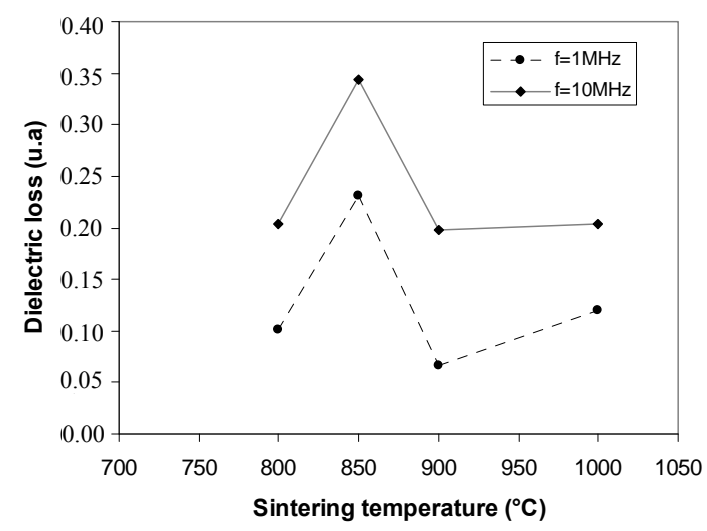

Figure 7. Variation of the dielectric loss versus the sintering temperature. is compressive which decreases significantly from -0.62 $\mathrm{GPa}$ at $700^{\circ} \mathrm{C}$ to $-0.2 \mathrm{MPa}$ at $1000^{\circ} \mathrm{C}$. The temperature dependence of electrical resistivity and dielectric constant were studied at room temperature for different frequencies ranging from $10^{-1} \mathrm{~Hz}$ until $10 \mathrm{MHz}$. Results show an increase of dielectric constants with increasing the sintering temperature and a decrease with changing the measuring frequency. This effect is attributed to the increase of grain size, deviation from stoichiometry and the decrease in sample strain.

Electrical resistivity was determined to be in the range $4 \times 10^{9}-2.4 \times 10^{10} \Omega \cdot \mathrm{cm}$ indicating a more dielectric behaviour than a semi-conducting character. All the above results show that the sample sintered at $900^{\circ} \mathrm{C}$ has the best dielectric properties and a good crystalline structure.

\section{REFERENCES}

[1] S. Gledhil, A. Grimm, A. Allsop, T. Koehler, C. Camus, L. Lux-Steiner and C.-H. Fisher, "A Spray Pyrolysis Route to the Undoped $\mathrm{ZnO}$ Layer of $\mathrm{Cu}(\mathrm{In}, \mathrm{Ga})(\mathrm{S}, \mathrm{Se})_{2}$ Solar Cells," Thin Solid Films, Vol. 517, No. 7, 2009, pp. 2309-2311. doi:10.1016/j.tsf.2008.10.110

[2] S. Major and K. L. Chopra, "Indium-Doped Zinc Oxide Films as Transparent Electrodes for Solar Cells," Solar Energy Materials, Vol. 17, No. 5, 1988, pp. 319-327. doi:10.1016/0165-1633(88)90014-7

[3] S. T. Shishiyanu, T. S. Shishiyanu and O. I. Lupan,"Sensing Characteristics of Tin-Doped $\mathrm{ZnO}$ Thin films as $\mathrm{NO}_{2}$ Gas Sensor," Sensors and Actuators B: Chemical, Vol. 107, No. 1, 2005, pp. 379-386.

doi:10.1016/j.snb.2004.10.030

[4] T. K. Gupta and J. Am, "Application of Zinc Oxide Varistors," American Ceramatic Society, Vol. 73, No. 7, 1990, pp. 1817-1840.

doi:10.1111/j.1151-2916.1990.tb05232.x

[5] S. Anas, R. V. Mangalaraja, M. Poothayal, S. K. Shukla and S. Ananthakumar, "Direct Synthesis of VaristorGrade Doped Nanocrystalline $\mathrm{ZnO}$ and Its Densification through a Step-Sintering Technique," Acta Materialia, Vol. 55, No. 17, 2007, pp. 5792-5801. doi:10.1016/j.actamat.2007.06.047

[6] Y. I. Alivov, E. V. Kalinina, A. E. Cherenkov, D. C. Look, B. M. Ataev, A. K. Omaev, M. V. Chukichev and D. M. Bagnall, "Fabrication and Characterization of $n-\mathrm{ZnO}$ / p-AlGaN Heterojunction Light-Emitting Diodes on 6H-SiC Substrates," Applied Physics Letters, Vol. 83, No. 23, 2003, pp. 4719-4721. doi:10.1063/1.1632537

[7] H. S. Kim, F. Lugo, S. J. Pearton, D. P. Norton, Y. L. Wang and F. Ren, "Phosphorus Doped ZnO Light Emitting Diodes Fabricated via Pulsed Laser Deposition," Applied Physics Letters, Vol. 92, No. 11, 2008, pp. 112108112110. doi:10.1063/1.2900711

[8] X. H. Yu, J. Ma, F. Ji, Y. H. Wang, X. J. Zhang and H. L. $\mathrm{Ma}$, "Influence of Annealing on the Properties of $\mathrm{ZnO}$ : Ga Films Prepared by Radio Frequency Magnetron Sputtering," Thin Solid Films, Vol. 483, No. 1-2, 2005, pp. 
296-300. doi:10.1016/i.tsf.2005.01.013

[9] J. Hu and R. G. Gordon, "Atmospheric Pressure Chemical Vapor Deposition of Gallium Doped Zinc Oxide Thin Films from Diethyl Zinc, Water, and Triethyl Gallium," Journal of Applied Physics, Vol. 72, No. 11, 1992, pp. 5381-5392. doi:10.1063/1.351977

[10] K. Y. Cheong, N. Muti and S. R. Ramanan, "Electrical and optical studies of $\mathrm{ZnO}$ : Ga Thin Films Fabricated via the Sol-gel Technique," Thin Solid Film, Vol. 410, No. 1-2, 2002, pp. 142-146. doi:10.1016/S0040-6090(02)00286-9

[11] A. Zaier, F. Oum Elaz, F. Lakfif, A. Kabir, S. Boudjadar and M. S. Aida, "A Novel Synthesis of Nanostructured $\mathrm{ZnO}$ via Thermal Oxidation of $\mathrm{Zn}$ Nanowires Obtained by a Green Route," Metirial Science in Semiconductor Processing, Vol. 12 ,2009, pp. 279-284.

[12] J. Nause and B. Nemeth, "Pressurized Melt Growth of ZnO Boules," Semiconductor Science and Technology, Vol. 20, No. 4, 2005, p. S45. doi:10.1088/0268-1242/20/4/005

[13] K. Jacobs, D. Schulz, D. Klimm and S. Ganschow, "Melt Growth of ZnO Bulk Crystals in Ir Crucibles," Solid State Sciences, Vol. 12, No. 3, 2010, pp. 307-310. doi:10.1016/j.solidstatesciences.2009.05.015

[14] Y. Caglar, S. Aksoy, S. Ilican and M. Cagmar, "Crystalline Structure and Morphological Properties of Undoped and Sn Doped ZnO Thin Films," Superlattices and Microstructures, Vol. 46, 2009, pp. 469-475. doi:10.1016/j.spmi.2009.05.005

[15] B. D. Cullity and S. R. Stock, "Elements of X-ray Diffraction," 3rd Edition, Prentice Hall, Upper Saddle River, 2001.

[16] F. Hamdani, A. Botchkarev, W. Kim, H. Morkoç, M. Yeadon, J. M. Gibson, S.-C. Y. Tsen, David J. Smith, D. C. Reynolds, D. C. Look, K. Evans, C. W. Litton, W. C. Mitchel and P. Hemenger, "Optical Properties of GaN Grown on ZnO by Reactive Molecular Beam Epitaxy," Applied Physics Letters, Vol. 70, No. 4, 1997, pp. 467469. doi:10.1063/1.118183

[17] A. Umar, S. H. Kim, Y. B. Hahn, "Sea-Urchin Like ZnO Nanostructures on Si by Oxidation of Zn Metal Powders: Structural and Optical Properties," Superlattices and Microstructures, Vol. 39, No. 1-4, 2006, pp. 145-152. doi:10.1016/j.spmi.2005.08.067

[18] N. Wang, J. Li, H. R. Peng and G. C. Li, "Synthesis of $\mathrm{ZnO}$ Nanostructures Composed of Nanosheets with Controllable Morphologies," Crystal Research Technology, Vol. 44, No. 3, 2009, pp. 341-345. doi:10.1002/crat.200800445

[19] L. Kumari and W. Z. Li, "Synthesis, Structure and Optical Properties of Zinc Oxide Hexagonal Microprisms," Crystal Research Technology, Vol. 45, No. 3, 2010, pp. 311315. doi:10.1002/crat.200900600

[20] E. M. Bachari, G. Baud, S. B. Amor and M. Jacquet, "Structural and Optical Properties of Sputtered $\mathrm{ZnO}$ Films," Thin Solid Films, Vol. 348, No. 1-2, 1999, pp. 165-172. doi:10.1016/S0040-6090(99)00060-7

[21] T. V. Vimalkumar, N. Poornima, C. S. Kartha and K. P.
Vijayakumar, "On Tuning the Orientation of Grains of Spray Pyrolysed ZnO Thin Films," Applied Surface Science, Vol. 256, No. 20, 2010, pp. 6025-6028. doi:10.1016/j.apsusc.2010.03.113

[22] M. Matsuoka and K. Ono, "Photochromism and Anomalous Crystallite Orientation of $\mathrm{ZnO}$ Films Prepared by a Sputtering-Type Electron Cyclotron Resonance Microwave Plasma," Applied Physics Letters, Vol. 53, No. 15, 1988, pp. 1393-1395. doi:10.1063/1.99987

[23] T. P. Rao, M. C. S. Kumar, A. Safarullaa, V. Ganesan, S. R. Barman and C. Sanjeeviraja, "Physical Properties of ZnO Thin films Deposited at Various Substrate Temperatures Using Spray Pyrolysis," Physica B: Condensed Matter, Vol. 405, No. 9, 2010, pp. 2226-2231. doi:10.1016/i.physb.2010.02.016

[24] M. K.Puchet, P. Y. Timbrell and R. N. Lamb, "Post Deposition Annealing of Radio Frequency Magnetron Sputtered ZnO Films," Journal of Vacuum Science \& Technology A, Vol. 14, No. 4, 1996, pp. 2220-2230. doi: $10.1116 / 1.580050$

[25] T. P. Rao and M. C. S. Kumar, "Effect of Thickness on Structural, Optical and Electrical Properties of Nanostructured $\mathrm{ZnO}$ Thin films by Spray Pyrolysis," Applied Surface Science, Vol. 255, No. 8, 2009, pp. 4579-4584. doi:10.1016/j.apsusc.2008.11.079

[26] H. Li, J. Wang, H. Liu, H. Zhang and X. Li, "Zinc Oxide Films Prepared by Sol-Gel Method," Journal of Crystal Growth, Vol. 275, No. 1-2, 2005, pp. 943-946. doi:10.1016/j.jcrysgro.2004.11.098

[27] J. W. Zhai, L. Y. Zhang and X. Yao, "The Dielectric Properties and Optical Propagation Loss of c-axis Oriented ZnO Thin Films Deposited by Sol-gel Process," Ceramics International, Vol. 26, No. 8. 2000, pp. 883-885. doi:10.1016/S0272-8842(00)00031-6

[28] H. Gomez, A. Maldonado, M. de la L. Olvera and D. R. Acosta, "Gallium-Doped ZnO Thin Films Deposited by Chemical Spray," Solar Energy Materials \& Solar Cells, Vol. 87, No. 1-4, 2005, pp. 107-116. doi:10.1016/j.solmat.2004.07.016

[29] M. de la L. Olvera, A. Maldonado, R. Asomoza and M. Meléndez-Lira, "Effect of the Substrate Temperature and Acidity of the Spray Solution on the Physical Properties of F-Doped $\mathrm{ZnO}$ Thin Films Deposited by Chemical Spray," Solar Energy Materials \& Solar Cells, Vol. 71, No. 1, 2002, pp. 61-71. doi:10.1016/S0927-0248(01)00044-7

[30] A. Zaier, F. Oum El az, F. Lakfif, A. Kabir, S. Boudjadar and M. S. Aida, "Effects of the Substrate Temperature and Solution Molarity on the Structural Opto-Electric Properties of ZnO Thin Films Deposited by Spray Pyrolysis," Materials Science in Semiconductor Processing, Vol. 12, No. 6, 2009, pp. 207-211.doi:10.1016/j.mssp.2009.12.002

[31] C. H. Pandis, N. Brilis, D. Tsamakis, H. A. Ali, S. Krishnamoorthy and A. A. Iliadis, "Role of Low $\mathrm{O}_{2}$ Pressure and Growth Temperature on Electrical Transport of PLD Grown ZnO Thin films on Si Substrates," Solid-State Electronics, Vol. 50, No. 6, 2006, pp. 1119-1123. doi:10.1016/j.sse.2006.04.025 